\title{
A ressonância do modelo analítico de Philip Tagg para os Estudos da Música no Cinema ${ }^{1}$
}

\author{
Suzana Reck Miranda ${ }^{2}$
}

${ }^{1}$ Artigo resultante de pesquisa com apoio financeiro do CNPq. Uma versão resumida deste tema foi apresentada no XVII Encontro Socine (Unisul, 2013).

${ }^{2}$ Professora do Departamento de Artes e Comunicação e do Programa de Pós-Graduação em Imagem e Som, ambos da UFSCar, onde ainda coordena o Grupo de Estudos do Som e da Música no Audiovisual (GESSOMA). Publicou vários artigos e capítulos de livros sobre a relação da música com outros meios, em especial com o cinema. 


\section{Resumo}

Este artigo destaca o modelo analítico do musicólogo britânico Philip Tagg no intuito de averiguar não apenas a contribuição pretendida pelo autor, mas também a ressonância de suas proposições nos Estudos da Música no Cinema. Nosso objetivo é colaborar com a discussão sobre os desafios envolvidos no caráter híbrido e interdisciplinar desta área de estudos.

Palavras-chave: Teoria da Música no Cinema; Musicologia; Philip Tagg; Estudos de Cinema.

\section{Abstract}

This paper is focused on Philip Tagg's analytical model in order to investigate both the intended contribution by the author and the resonance of his propositions in Film Music Studies. Our aim is to contribute to the debate about the challenges implied by the hybrid nature of this specific area (in which Musicology and Film Studies are intertwined).

Keywords: Film Music Theory; Musicology; Philip Tagg; Film Studies. 
Se considerarmos o quanto os Estudos da Música no Cinema se desenvolveram a partir de 1990, talvez soe injusto iniciar este texto destacando o tom pessimista que reverbera nas afirmações de David Neumeyer. O autor, mesmo pontuando tal expansão a partir do marco citado, acredita que este recorte teórico ainda não tem um papel relevante dentro do largo espectro de suas disciplinas geradoras, a Musicologia e os Estudos de Cinema (BUHLER, FLINN \& NEUMEYER, 2000: 2).

Esta situação decorreria, em parte, devido ao longo período no qual, nos Estudos de Cinema, som e música foram temas periféricos diante do domínio imagético. Já na Musicologia, a despeito de ter sido academicamente estruturada há mais tempo, a principal barreira foi o dominante alinhamento com a História da Música Ocidental e com análises formalistas de obras consideradas "artísticas".

Duprat nos lembra de que a Musicologia surgiu como disciplina no final do século XIX, no "clima epistemológico do positivismo cientificista" (DUPRAT, 2007: 7). Nattiez acrescenta que Guido Adler $^{3}$ a dividiu - em seu importante texto publicado em 1885 - em duas correntes principais: a 'Musicologia Histórica', que envolveria o estudo da notação, das formas musicais e suas evoluções, das regras de composição e da organologia; e a 'Musicologia Sistemática', dedicada à estética, à psicologia da música, à educação musical e ao que hoje chamamos de Etnomusicologia (NATTIEZ, 2005: 8). No entanto, o que de fato despontou e tornou-se dominante foi a primeira corrente.

Só no início do século XX é que músicas de tradições orais não ocidentais adentram o espaço acadêmico (até então tomado pelos cânones da música erudita ocidental) e começam a ser rigorosamente estudadas. Pesquisadores de Berlim, na Alemanha, denominaram este tipo de abordagem de 'Musicologia Comparada'. Bastos acredita que em decorrência da necessidade de se estudar este tipo de música sem desvinculá-la do comportamento humano, houve uma aproximação inevitável da área com a Antropologia e o termo Etnomusicologia passou a ser

\footnotetext{
${ }^{3}$ Trata-se da seguinte publicação: ADLER, Guido "Umfang, Methode und Ziel der Musikwissenschaft", Vierteljahrschrift für Musikwissenschaft, vol. I, 1885, p. 5-20.
} 
amplamente adotado (BASTOS, 1995: 9-73) ${ }^{4}$.

Tanto a Musicologia quanto a Etnomusicologia disseminam-se nas universidades norte-americanas e europeias a partir da década de 1950 e, aos poucos, vão mutuamente reconhecendo a necessidade da interdisciplinaridade. Mas isto não significa que as diferentes abordagens não tenham lidado com tensões constantes. De um lado, havia os que, apoiados nas ideias utópicas de Charles Seeger ${ }^{5}$, defendiam que a Etnomusicologia e Musicologia Histórica deveriam ser consideradas "subdivisões" da Musicologia, uma vez que esta última seria "o campo de estudo completo" da música na cultura humana. De outro, estavam os que discordavam e que viam no importante livro de Alan Merriam ${ }^{6}$ uma espécie de guia metodológico para a Etnomusicologia, pois acreditavam que as abordagens musicológicas, de um modo geral, tendiam a supor um conhecimento da música focado em compositores e obras, enquanto que o interesse da Etnomusicologia deveria centrar-se nos eventos, nas interpretações ou, como Titon (1997: 25-42) proporá anos mais tarde, "no estudo das pessoas fazendo música"”.

Béhague pontua que, até há pouco tempo, a maioria dos musicólogos deu maior valor artístico às "obras primas" que se sustentam (segundo eles próprios concebem) em suas qualidades intrínsecas e não àquelas que se baseiam em elementos extramusicais (BÉHAGUE, 2006: 64). Tal predomínio é reforçado por Cook, que chega a apontar o fato de que nas universidades havia um repertório que era considerado "apropriado" para a investigação acadêmica (COOK, 2006: 9).

Os desdobramentos foram inúmeros e originaram a chamada "nova musicologia", fomentada inicialmente a partir de diferentes colocações feitas em

\footnotetext{
${ }^{4} \mathrm{O}$ citado texto de Rafael J.M. Bastos parte de uma breve exposição da conformação das muitas "musicologias" e apresenta um excelente panorama sobre a definição da Etnomusicologia enquanto campo de estudo.

${ }^{5}$ Ver: SEEGER, Charles. Studies in Musicology: 1935-1975. Berkeley: University of Califomia Press, 1977.

${ }^{6}$ MERRIAN, Alan. The Antropology of Music. Chicago: Northwestern University Press, 1964.

${ }^{7}$ Jeff T. Titton, em artigo publicado no livro Shadows in the Field: New Perspectives for Fieldwork in Ethnomusicology (1997), fala de uma "music-making epistemology" e da experiência de "knowing people through 'musical being".
} 
resposta ao importante livro de Joseph Kerman (Contemplating Music: Challenges to Musicology) de $1985^{8}$. Não é nosso objetivo delimitar o amplo conjunto de ideias e práticas que surgiram nestas últimas décadas - encabeçadas por nomes como Gary Tomlinson ${ }^{9}$, Susan McClary ${ }^{10}$ e muito outros. Queremos apenas frisar que os limites das abordagens foram estendidos e que há uma preocupação constante em não considerar a música como algo que opera de forma estrita e autônoma. Já nos disse Duprat (2007: 14) que hoje a interdisciplinaridade é aceita por todos e que é impossível delimitar rigorosamente áreas e subáreas. No entanto, vale ressaltar que isto não significa que localizar os Estudos da Música no Cinema dentro deste contexto seja uma tarefa mais simples nos dias atuais.

Em relação aos Estudos do Cinema, a situação não é menos complexa. Em artigo conjunto com James Buhler, Neumeyer aponta, por exemplo, que os primeiros textos sobre música e cinema publicados após o advento do som sincronizado ao filme foram escritos por compositores (Morton, Sternfeld, London, Sabaneev, Eisler, entre outros), o que explicaria o foco maior em práticas musicais e não nos efeitos da interação entre música, narrativa e aspectos visuais (NEUMEYER \& BUHLER, 1994: 369).

Esboços modestos sobre esta interação apareceram nas primeiras teorias sobre o uso geral do som no cinema, que surgiram logo após a consolidação do cinema sonoro, momento em que realizadores e teóricos se preocuparam com uma possível ameaça do som à especificidade cinematográfica conquistada pela imagem silenciosa. De diferentes formas, muitos textos ${ }^{11}$ deste período (como os de Serguei Eisenstein ([1928] 1985), Jean Epstein ([1947] 1985) René Clair ([1930] 1985) e de Rudolf Arnheim ([1938] 1985), por exemplo) preocuparam-se em

\footnotetext{
${ }^{8}$ Este livro foi traduzido para o português por Álvaro Cabral: KERMAN, Joseph. Musicologia. São Paulo: Martins Fontes, 1987.

${ }^{9}$ TOMLINSON, Gary. Music in renaissance magic: Toward a historiography of others. Chicago: University of Chicago Press, 1994.

${ }^{10}$ McCLARY, Susan. Feminine Endings: Music, Gender, and Sexuality. Minneapolis: University of Minnesota Press, 1991.

${ }^{11}$ Os textos citados podem ser encontrados no livro Film Sound: Theory and Practice (1985), editado por WEISS, E. \& BELTON, J.
} 
denunciar o uso abusivo da voz em sincronia e defendiam que o som deveria acrescentar elementos à narrativa ao invés de redundá-la. No entanto, estas discussões iniciais não detalharam questões relativas à música. Textos posteriores é que a destacaram mais, embora raramente em publicações específicas.

É esta separação, de certo modo ainda presente, que motivou o diagnóstico pessimista de Neumeyer. O problema, segundo ele, está na "interdisciplinaridade irredutível" $^{12}$ (BUHLER, FLINN \& NEUMEYER, 2000: 2) que faz com que musicólogos deplorem interpretações superficiais de quem não possui um conhecimento musical amplo, da mesma forma que os teóricos do cinema criticam as análises musicais que não levam em consideração os elementos cinematográficos.

O interesse acadêmico em som/música no cinema cresceu notoriamente após a chamada era Dolby (final dos anos 1970), momento no qual uma maior integração entre os elementos sonoros foi tecnicamente viabilizada. Na década seguinte, na França, o também músico Michel Chion desponta como uma referência de peso nos estudos sobre som no cinema, mantendo-se nesta posição até hoje. Perpassando a Fenomenologia e os caminhos do compositor Pierre Schaeffer, suas obras exploram uma espécie de teoria da interação entre som e imagem cujo paradigma principal está baseado em relações sinérgicas, defendendo que o modo de ouvir afeta o modo de ver e vice-versa. Sua obra é vasta e explora não apenas efeitos sonoros e ruídos, mas também o uso da voz e da música em filmes ${ }^{13}$.

Paralelamente, outra produção teórica surge nos Estados Unidos, específica sobre música e cinema, que tenta, num esforço nem sempre unanimemente reconhecido, dialogar com os dois campos disciplinares geradores. Tais abordagens focaram, sobretudo, a tradição da chamada "época de ouro", voltandose para as funções e a estética das partituras (com linguagem sinfônica), originalmente compostas para o cinema hollywoodiano entre os anos 1930 e 1940.

Um marco deste campo híbrido - ainda sem um local exatamente definido nas

\footnotetext{
${ }^{12}$ Termo original: irreducible interdisciplinarity.

${ }^{13}$ Até o momento, La Musique au Cinéma, publicado em 1995 pela Fayard, é o único livro que Chion dedicou especificamente às questões musicais no cinema.
} 
áreas - foi, sem dúvida, a obra de Claudia Gorbman, Unheard Melodies - Narrative Film Music, publicada em 1987. O livro tornou-se referência por iniciar uma discussão acadêmica rigorosa que abrangeu tanto os Estudos de Cinema como determinadas questões que integram e conformam a Musicologia. Entre os argumentos que a autora explora um dos que mais repercutiu foi sua afirmação categórica de que a música típica do cinema narrativo clássico permanece a maior parte do tempo imperceptível para o espectador - ou "transparente", para adotarmos um conceito caro aos Estudos de Cinema -, na medida em que favorece os elementos narrativos do filme. Além disso, a autora não ignora o binômio música/cinema, criando termos que os distinguem, sem que tal caminho de análise deixe de enfocar com profundidade autores como Jean-Louis Baudry, nome importante para a teoria do cinema.

A posição de Gorbman, portanto, desafia - de certa forma - os argumentos centrais da "irredutibilidade" apontada por Neumeyer, que se sustenta no "desconhecimento" inerente de um dos campos. Ou seja, para ele, tanto os músicos rejeitam as interpretações limitadas de quem não possui um conhecimento musical consistente, quanto os teóricos do cinema desprezam as análises musicais que desconsideram os elementos cinematográficos. Assim, com Gorbman, estes universos comumente separados, no mínimo, tornaram-se mais próximos, e criaram uma sequência de estudos que se dedicou a ampliá-la ou questioná-la, tais como o fizeram Caryl Flinn e Kathryn Kalinak, autoras, respectivamente, de Strains of Utopia: Gender, Nostalgia and Hollywood Film Music e de Settling the Score: Music and Classical Hollywood Film, contribuindo para a produção de um escopo teórico que ganha, assim, visibilidade e volume ${ }^{14}$.

Nosso objetivo neste artigo é destacar que os Estudos da Música no Cinema, tendo em vista o seu caráter híbrido e interdisciplinar, podem receber valiosas contribuições de autores que não necessariamente, como Gorbman e Chion, transitam com notória destreza entre as fronteiras das disciplinas ditas geradoras

\footnotetext{
${ }^{14}$ Abordamos detalhadamente este escopo teórico em outro artigo: "O legado de Gorbman e seus críticos para os Estudos da Música no Cinema”, publicado em CONTRACAMPO/UFF. Niterói, $n^{\circ} 23$, dezembro de 2011, p 160-170.
} 
(Musicologia e Estudos de Cinema). Como exemplo, tomaremos o modelo analítico do musicólogo britânico Philip Tagg (oriundo do seu longo estudo sobre a música popular) no intuito de averiguar não apenas a contribuição pretendida pelo autor, mas também possíveis ressonâncias de suas proposições no recorte teórico específico da música no cinema.

\section{Ecos musicológicos e novos olhares}

Conhecido pela postura crítica em relação ao modo como o conhecimento musical é disseminado no meio acadêmico, Philip Tagg foi um dos pioneiros em estudos rigorosos sobre Música Popular e membro fundador da IASPM (International Association for the Study of Popular Music), no início da década de 1980. Desde suas primeiras pesquisas, dedicou-se a desenvolver um modelo analítico que, além dos elementos estruturais, levasse em consideração o que ele chama de contexto paramusical, no qual as significações musicais são necessariamente compreendidas para além de seus elementos intrínsecos.

O tema de abertura da série de TV Kojak (EUA, CBS, 1973-1978) foi um dos seus primeiros objetos de análise, fato que já revela o interesse do musicólogo pela sinergia da música com os meios audiovisuais. Tal pesquisa gerou o livro Kojak - 50 Seconds of Television Music (1979), no qual analisa um único exemplo musical (com 50 segundos de duração), e nele consegue enumerar 43 características diferentes (relacionadas ao tempo, aos timbres, a parâmetros acústicos, efeitos de estúdio, contornos melódicos, entre outras). Tagg quis demonstrar que análises musicológicas usuais não são capazes de gerar resultados como este, uma vez que priorizam os elementos que constituem a composição musical em si, sem levar em consideração uma série de características que são fundamentais no universo da música popular como, por exemplo, o fato de circular como um produto comercial entre públicos muitas vezes heterogêneos e/ou a sua principal forma de registro não ser a notação musical convencional. Este diagnóstico foi reforçado em suas pesquisas posteriores, bem como no emblemático livro Fernando the flute (1991), no qual analisa a canção 
Fernando, um sucesso de vendas do grupo sueco ABBA.

Tagg notou que, de um modo geral, os descritores analíticos comumente utilizados sobrevalorizam elementos inerentes ao 'fazer' musical. Trata-se de uma terminologia que permite ao analista reconhecer e identificar elementos que constituem uma peça musical, bem como técnicas empregadas na sua execução, mas que, no entanto, não contempla características ligadas à 'recepção' musical. $O$ autor identificou uma carência de termos capazes de denotar efeitos perceptivos e/ou conotações culturalmente específicas e tal situação, em sua opinião, restringiria o reconhecimento e a distinção de sons musicais apenas a sujeitos com formação em música (TAGG, 1982: 40-43).

Em detrimento disto, as abordagens de Tagg partem do princípio de que a música é um sistema simbólico e que o seu poder de comunicação é tão dependente das competências perceptivas das pessoas que não possuem formação em música (as quais ele denomina "não musos") quanto das que possuem (Cf. TAGG, 2001). Defende que todas as pessoas deveriam ter acesso ao entendimento de como a música afeta e gera compreensões. Para o autor, descritores ligados apenas ao fazer musical não são suficientes (um mesmo acorde, por exemplo, pode suscitar ideias diferentes em diferentes obras), principalmente porque não contemplam relações com fenômenos não musicais (paramusicais). Neste sentido, sugere que os musicólogos precisam pensar em descritores estruturais mais democráticos (TAGG, 2001: 4).

Resumidamente, o modelo semioticamente orientado de Tagg consiste em identificar, na obra musical, musemas (conceito originalmente elaborado por Charles Seeger, em 1960, que diz respeito a unidades mínimas de significação ${ }^{15}$ ) e, logo após, observar as associações paramusicais possíveis que estes musemas, em uma prática cultural específica, podem suscitar. $\mathrm{O}$ autor esclarece que os musemas (e suas associações) são semelhantes a outros musemas de outras músicas e que esta característica permite ao analista encontrar um possível significado (para o evento sonoro) a partir de uma "correspondência hermenêutica" (entre eventos distintos).

${ }^{15}$ Cf. TAGG, 1979: 71. Nome original: museme ([Seeger, 1960: 76] apud TAGG, 1979:71). 
Consequentemente, duas etapas são imprescindíveis em seu método. A primeira implica em observar os musemas da música analisada em relação a outros, de outras obras, que sejam semelhantes, desde que estas obras tenham sido concebidas dentro de um mesmo contexto cultural. Após, os musemas devem ser relacionados aos seus possíveis contextos paramusicais (letra, cenários, ações, habitat social, entre outros).

Leitor e crítico atento, Tagg tangenciou várias faces da Musicologia, entre as quais destacamos os estudos da Semiologia aplicados à Música (NATTIEZ, 1975; MOLINO, 1975 e RUWET, 1972, entre outros) e chegou a usar em um de seus artigos a polaridade poiético/estésico - derivada de Jean Molino - para traçar as diferenças entre o fazer musical e a percepção/recepção da música (Cf. TAGG, 2001) ${ }^{16}$. Costuma também explicitar a especificidade do discurso musical e as dificuldades em delimitar os referentes simbólicos, indiciais e/ou iconicidades com algo extrínseco a sua estrutura. É neste horizonte que ele define as associações paramusicais como aquelas que podem ser construídas tanto por semelhanças sonoras quanto cinéticas. Tais associações podem derivar, por exemplo, de relações de causalidade (ou proximidade) entre o fragmento musical analisado e o que quer que a ele possa estar conectado (uma semelhança acústica, uma analogia sinestésica, uma determinada prática social, entre outros).

No intuito de aprimorar tal modelo, Tagg e Clarida empreenderam uma longa pesquisa empírica entre 1979 e 1985 que, posteriormente, foi compilada no livro Ten Little Title Tunes, publicado em 2003. Trechos musicais pequenos, retirados de exemplos fílmicos e televisivos, ${ }^{17}$ foram reproduzidos sem as imagens a

\footnotetext{
${ }^{16}$ Sobre a origem dos termos poiético/estésico - ver: MOLINO, Jean. "Fait musical et sémiologie de la musique" in: Music en jeu n.17, 1975, p.37-62. Há uma tradução para o português deste texto em NATTIEZ, J.J; ECO,U. Et. al. Semiologia da Música, Lisboa: Vega Universidade, s/d.

${ }^{17}$ Exemplos foram extraídos das séries de TV Monty Python's Flying Circus (UK, BBC, 1969-1974), Miami Vice (EUA, NBC, 1984-1987), dos filmes Um bonde chamado desejo (EUA, Elia Kazan, 1951), Romeu e Julieta (UK, Franco Zefirelli, 1968), entre outros.
} 
centenas de pessoas ${ }^{18}$ que, num curto espaço de tempo, tiveram que descrever configurações visuais que julgavam equivalentes, a partir de exercícios de pensamento associativo. Foram feitos cruzamentos estatísticos rigorosos e as tabelas resultantes passaram a constituir o que os autores chamaram de material de 'comparação interobjetiva'19 .

Os autores analisaram os resultados detalhadamente, levantaram possíveis razões musicais para as associações dos ouvintes e as examinaram intrínseca e extrinsecamente. Posteriormente, situaram tais características musicais em um campo abrangente do discurso musical ocidental e de suas interações sociais. Embora o modelo analítico de Tagg vez ou outra seja contestado, ecoou notoriamente em duas importantes publicações sobre a interação música/cinema, conforme explicitaremos logo mais.

Como já dissemos, Tagg (e também Clarida) defende a busca por um vocabulário no qual "musos" e "não musos" possam relacionar certas sonoridades não apenas de uma maneira estruturalmente correta, mas fenomenologicamente coerente. Por essa razão é que o livro Ten Little Title Tunes demonstra um esforço em dissecar relações comuns e estereotipadas, bem como em fornecer meios para conhecer e reconhecer os arquétipos de nossa própria cultura.

Neste horizonte, não por acaso, boa parte da construção do vocabulário baseou-se nas sugestões ocorridas durante os testes empíricos. Tagg e Clarida elaboraram descritores estruturais a partir de termos coloquiais e incorporaram desde descritores de timbres (baseados em rótulos de samplers, de softwares), de parâmetros (inspirados em templates de equipamentos via termos como reverb, delay, entre outros), descritores conotativos (a partir de bibliotecas de exemplos musicais), até títulos de fonogramas, de partituras. Em um de seus testes/exercícios recentes, por exemplo, Tagg usou como referência títulos e

\footnotetext{
${ }^{18}$ Foram cerca de 600 pessoas de três países (Suécia, Canadá e Inglaterra), sendo que a maioria foi composta por alunos que frequentaram seus cursos de análise da música popular, com ou sem formação musical.

${ }^{19}$ Termo original: interobjective comparison (TAGG \& CLARIDA, 2003: 96).
} 
estruturas musicais da compilação de partituras de Erno Rappé ${ }^{20}$, destinada ao acompanhamento musical de filmes na época do cinema silencioso (Cf. TAGG, 2012). Cabe ressaltar ainda que seus descritores também abarcam termos musicais como stacatto, glissando, crescendo, diminuendo, desde que sejam plausíveis para "não musos".

As sugestões analíticas de Tagg envolvem também uma disposição cronométrica exata do exemplo analisado bem como a elaboração de uma espécie de partitura gráfica, com linhas para o tempo, para a forma, para a ocorrência de musemas, entre outras. $\mathrm{O}$ autor frisa ainda que não existe - e nem pode existir um "dicionário" de musemas. Ou seja, para cada análise, uma tabela de ideias musicais deve ser elaborada (TAGG, 1979, 2003).

Diante do exposto, queremos destacar o seguinte fato: embora o empreendimento Tagg, de um modo geral, centra-se na elaboração de um modelo analítico mais "democrático" para a música popular, sua principal estratégia envolveu analisar trechos musicais acoplados a imagens (trechos de filmes, vinhetas, programas e comerciais de TV), bem como ministrar cursos universitários de música para cinema e TV - para alunos de comunicação e de música simultaneamente (TAGG, 2003, 2012).

Consequentemente, é possível compreender a ressonância, mesmo que breve, de suas ideias já nos nascentes estudos teóricos da Música de Cinema da década de 1980. Kathryn Kalinak, em artigo importante de $1982^{21}$, usou o estudo empírico de Tagg e Clarida (que, na época ainda era um relatório de pesquisa e não o livro) para analisar exemplos de temas musicais que suscitam associações com a figura feminina (temas pastorais, românticos, elementos rurais, entre outros). Kalinak cruzou os seus registros sobre a representação musical da esposa virtuosa (em filmes clássicos hollywoodianos) com as estruturas musicais que foram ligadas à figura feminina nos estudos de Tagg/Clarida (melodias sem síncopes, com notas em legato, com progressões harmônicas direcionais, entre outras características).

\footnotetext{
${ }^{20}$ RAPPÉ, Erno. Motion Picture Moods for Pianists and Organists. New York: Arno, [1 ${ }^{\mathrm{a}}$ Ed.1924] 1974.

21 "The Fallen Woman and the Virtuous Wife: musicals stereotypes in The Informer, Gone with the Wind, and Laura" in: Film Reader vol. 5, pp 76-82.
} 
Outro eco importante encontra-se no trabalho de Anahid Kassabian, que conheceu Tagg no final da década de 1980, na Universidade de Gotemburgo, durante seu doutoramento ${ }^{22}$. Atualmente, ela é professora titular na Universidade de Liverpool, no mesmo Departamento onde Tagg permaneceu por 10 anos $^{23}$. No seu livro Hearing Films: tracking identification in Contemporary Hollywood Film Music (2001), ela relacionou uma série de características dos resultados obtidos por Tagg e Clarida com algumas teorias feministas ${ }^{24}$ que também foram baseadas em oposições, uma vez que os ouvintes de Tagg e Clarida propuseram associações através de oposições binárias (como, por exemplo, mobilidade/cidade com homens e imobilidade/natureza com mulheres).

Dialogando majoritariamente com abordagens dos chamados Estudos Culturais, Kassabian foca sua reflexão nos processos de recepção dos filmes, sobretudo nos mecanismos de engajamento e identificação. Como outros autores, ela transita pela Teoria do Cinema e pela Musicologia, mas agrega ao seu repertório os Estudos da Música Popular, uma vez que não se detém, como Kalinak, em composições instrumentais originais do cinema clássico hollywoodiano, mas sim nas compilações de músicas populares em filmes comerciais das décadas de 1980 e 1990. Seu alvo é demonstrar que há algo a mais nesta opção por compilações do que apenas um fator de mercado. Ela acredita que as narrativas hollywoodianas, anteriormente alinhadas a ideologias masculinas (nos filmes dos anos 30-40, por exemplo), abriram espaço para personagens femininas que não representam mais aquela mulher ideal do cinema

\footnotetext{
${ }^{22}$ Kassabian fez seu doutorado na Universidade Stanford (EUA) e passou uma temporada na Suécia sendo aluna de Tagg.

${ }^{23}$ Philip Tagg foi professor na Universidade de Gotemburgo (Suécia) entre 1980 e 1991. Depois, mudou-se para o Departamento de Musicologia da Universidade de Liverpool (UK), onde permaneceu até 2002. Entre 2002 e 2009, foi Professor de Musicologia na Faculdade de Música da Universidade de Montreal (Canadá). Desde 2010, é Professor Visitante nas Universidades de Huddersfield e de Salford, ambas na Inglaterra.

${ }^{24}$ Dentre os textos que Kassabian cita, estão: LAURETIS, Teresa de (1984). "Desire in Narrative" in: Alice Doesn't: feminism, semiotics, cinema. Bloomington: Indiana University Press e KAPLAN, E. Ann (1978). Woman in film noir. London: British Film Institute.
} 
das décadas passadas e que isso, entre outras coisas, propicia relações distintas na articulação música/imagem.

Destacando que há pouca referência à música na literatura sobre o modo como o cinema hollywoodiano engaja o espectador em processos de identificação, Kassabian afirma enfaticamente que qualquer abordagem sobre o tema deve levar em conta a relação entre o espectador e a trilha musical. Para ela, o que gera consistência tanto na codificação quanto na decodificação das significações possíveis da música em filmes é o que ela chama de "competência", uma habilidade culturalmente adquirida, variável, que funciona entre "falantes de uma mesma linguagem", cuja consistência varia de acordo com o grau de "fluência" (Cf. KASSABIAN, 2001). Em decorrência disto é que as 'comparações interobjetivas' empregadas por Tagg/Clarida a interessaram sobremaneira, mesmo pontuando aspectos que julgou serem problemáticos.

\section{Dissonâncias}

Recentemente, em artigo-resposta para o IASPM@ Journal (vol. 3 n.2, 2013), Kassabian foi mais enfática na crítica às proposições de Philip Tagg. Esta edição trouxe um dossiê especial, dedicado a responder ao artigo que o musicólogo publicou no volume anterior (vol. 2, n.1, 2011) especialmente para comentar os 30 anos de existência da IASPM. No referido texto ${ }^{25}$, Tagg - enquanto membro fundador da mencionada associação - descreve que os objetivos iniciais da IASPM eram ser uma organização interdisciplinar, internacional e multiprofissional, pelas seguintes razões:

A impossibilidade de compreender a Música Popular sem considerar seus vários campos: o fazer musical, aspectos musicológicos, antropológicos, sociológicos, psicológicos, acústicos, entre outros;

Como há muitos tipos de música no mundo, é preciso que esta associação leve

\footnotetext{
25 "Caught on the back foot: epistemic inertia and visible music" in: IASPM@Journal (Journal of The International Association for the Study of Popular Music) vol. 2, n.1, 2011.
} 
isto em conta;

É preciso também considerar as múltiplas funções envolvidas na Música Popular: o compositor, o intérprete, o DJ, o produtor, os colecionadores, entre outros.

Em seguida, expôs que, em sua opinião, a associação falhou em inúmeros aspectos, dentre os quais, destacou o uso 'não crítico' da terminologia convencional da musicologia para, segundo ele, inadequadamente denotar as práticas estruturais da Música Popular. Outro ponto que Tagg destacou foi a falta de interesse entre os membros da IASPM em um tema que considera urgente: a (por ele chamada) música invisível ${ }^{26}$, que diz respeito a uma música que se apresenta em uma condição de escuta que não a coloca em primeiro plano, ou seja, trata-se daquela música que circula junto com imagens, propagandas, situações de consumo, que é pano de fundo de salas de espera, consultórios, lojas, entre outros.

Em sua resposta ${ }^{27}$, Kassabian criticou Tagg em quatro aspectos. Primeiramente, apontou que, embora Tagg defenda uma diversidade temática, ele próprio não costuma dialogar com as pesquisas distintas de seus pares. $O$ segundo aspecto negativo, que na opinião de Kassabian decorre do primeiro, é haver na obra de Tagg muita autocitação. "Nós fazemos um desserviço a nós mesmos ao não citarmos outros estudiosos que escrevem sobre temas semelhantes" ${ }^{28}$, afirma a autora (KASSABIAN, 2013a: 88). Já o terceiro é um aspecto metodológico. Kassabian não acha pertinente excluir a importância de se pensar os musemas também em uma relação intrínseca, dentro de uma única obra (a ênfase de Tagg repousa na comparação entre musemas de diferentes obras, bem como nas associações paramusicais por eles suscitadas). Por fim, Kassabian

\footnotetext{
${ }^{26}$ Termo original: invisible music.

27 "You Say Invisible, I Say Ubiquitous: A (Formally Former) Student's Response to Philip Tagg's 'Caught on the Back Foot: Epistemic Inertia and Visible Music'” in: IASPM@Journal, vol.3 n.2, 2013, pp.86-95.

${ }^{28}$ Frase original: we do ourselves a disservice by not citing the other scholars who write about similar topics.
} 
destaca que o que Tagg chama de música invisível é praticamente a mesma coisa que ela chama de música onipresente ${ }^{29}$, embora seus pontos de vista sejam diferentes. Para Tagg, a falta de interesse neste tipo de ocorrência musical deriva, em parte, de uma falta de atenção que é própria à recepção deste tipo de música. Kassabian, por outro lado, acha que o desinteresse relaciona-se com certo desconforto que ela sempre notou na IASPM em relação à música produzida deliberadamente para fins comerciais, fato que delimitou uma preferência dos pesquisadores em estudos que envolvem uma escuta "atenta".

Este tipo de debate, em nossa opinião, é fundamental e contribui para que os estudos específicos sobre a música no cinema reverberem em outros patamares. O intercâmbio entre pesquisadores que, de algum modo, encontram-se imersos no híbrido recorte dos Estudos da Música no Cinema com aqueles mais localizados em uma das disciplinas geradoras é o que pode fomentar o tão desejado papel "mais relevante" que Neumeyer desacredita. Mesmo diante do difícil desafio de lidar com áreas tão abrangentes, a aproximação de determinados aspectos de uma e/ou de outra vertente poderá suscitar cruzamentos importantes e remodelar paradigmas.

Para concluir, queremos destacar que - talvez - a principal ressonância das ideias de Tagg para os Estudos da Música de Cinema ainda esteja por vir: o musicólogo termina o seu citado artigo de 2011 lamentando a escassez de trabalhos sobre música/cinema ou música/audiovisual no âmbito da IASPM, e afirma que, principalmente em relação ao tema "música invisível", pesquisas com música e imagem em movimento poderão ajudar a solucionar problemas epistemológicos centrais nos Estudos da Música Popular. Quem sabe, a partir deste apelo, novas interfaces ocorram - inclusive em solo brasileiro.

\footnotetext{
${ }^{29}$ Termo original: ubiquitous music. Maiores detalhes podem ser encontrados em seu recente livro: Ubiquitous listening: affect, attention, and distributed subjectivity. Los Angeles/London, University of California Press, 2013b.
} 


\section{Referências Bibliográficas}

BASTOS, Rafael J. de Menezes. "Esboço de uma Teoria da Música: Para Além de uma Antropologia sem Música e de uma Musicologia sem Homem". Anuário Antropológico/93. Rio de Janeiro: Tempo Brasileiro, 1995, p. 9-73.

BÉHAGUE, Gerard. 'Música 'erudita', 'folclórica' e 'popular' do Brasil: Interações e inferências para a musicologia e etnomusicologia modernas". Latin American Music Review, Volume 27, n. 1, 2006, p. 57-68.

BUHLER, James; FLINN, Caryl \& NEUMEYER, David. (eds.) Music and Cinema. Hanover: Wesleyan University Press, 2000.

CHION, Michel. La Musique au Cinéma - Les chemins de la musique. Paris: Fayard, 1995.

COOK, Nicholas. "Agora somos todos (etno)musicólogos. [Trad. Pablo Sotuyo Blanco]. Ictus - Periódico do PPGMUS/UFBA, Vol. 7, 2006, p. 7-32.

DUPRAT, Régis. "A musicologia à luz da hermenêutica". Claves, n.3, maio 2007, p. 7-19.

GORBMAN, Claudia. Unheard Melodies: Narrative Film Music. Bloomington: Indiana University Press, 1987.

FLINN, Caryl. Strains of Utopia: Gender, Nostalgia and Hollywood Film Music. Princeton: Princeton University Press, 1992.

KALINAK, Kathryn. "The Fallen Woman and the Virtuous Wife: musicals stereotypes in The Informer, Gone with the Wind, and Laura". Film Reader, vol. 5, 1982, p. 76-82.

Settling the Score: Music and Classical Hollywood Film. Madison: University of Wisconsin Press, 1992.

KASSABIAN, Anahid. Hearing Films: tracking identification in Contemporary Hollywood Film Music. New York/London, Routledge, 2001.

"You Say Invisible, I Say Ubiquitous: A (Formally Former) Student's Response to Philip Tagg's 'Caught on the Back Foot: Epistemic Inertia and Visible Music" in: IASPM@Journal (Journal of The International Association for the Study of Popular Music), vol.3 n.2, 2013a, p.86-95.

Ubiquitous listening: affect, attention, and distributed subjectivity. Los Angeles/London, University of California Press, 2013b. 
McCLARY, Susan. Feminine Endings: Music, Gender, and Sexuality. Minneapolis: University of Minnesota Press, 1991.

MERRIAM, Alan P. The Anthropology of Music. Northwestern University Press, 1964.

MOLINO, Jean. "Fait musical et sémiologie de la musique" in: Music en jeu n.17, 1975 , p.37-62.

NATTIEZ, Jean-Jacques. Fondements d'une sémiologie de la musique. Paris, UGE, 1975.

[Trad. Luiz Paulo Sampaio] "O desconforto da Musicologia" in: Per Musi: Revista Acadêmica de Música, n. 11, 2005, p. 5-18.

NEUMEYER, David \& BUHLER, James. "Film Music/Film Studies" in: Journal of the American Musicological Society 47, n. 2, 1994, p. 364-385.

RAPPÉ, Ernő. Motion Picture Moods for Pianists and Organists. [1 ${ }^{a}$ Ed. 1924] New York: Arno, 1974.

RUWET, Nicolas. Langage, musique, poésie. Paris, Seuil, 1972.

SEEGER, Charles. $\quad$ Studies in Musicology: 1935-1975.

Berkeley: University of California Press, 1977.

TAGG, Philip. Kojak - 50 Seconds of Television Music. [1 ${ }^{\text {a }}$ Ed. 1979]. New York: Mass Media Music Scholars' Press, 2000.

"Analysing Popular Music: Theory, Method and Practice" in: Popular Music, Cambridge University Press Vol. 2, Theory and Method, 1982, p. 37-67

"Music analysis for 'non-musos': popular perception as a basis for understanding musical structure and signification" in: Conference on Popular Music Analysis (invited paper). University of Cardiff, November, 2001.

\& CLARIDA, Bob. Ten Little Title Tunes. New York/Montréal: Mass Media Music Scholars' Press, 2003.

"Caught on the back foot: epistemic inertia and visible music" in: IASPM@Journal (Journal of The International Association for the Study of Popular Music) vol. 2, n.1, 2011, p. 3-17.

"Music, Moving Image, and the "Missing Majority": How Vernacular Media Competence Can Help Music Studies Move into the Digital Era" in: Music and the Moving Image, University of Illinois Press, vol. 5, No. 2 (Summer 2012), p. 9-33. 
TITON, Jeff T. "Knowing Fieldwork". In Shadows in the Field: New Perspectives for Fieldwork in Ethnomusicology. Ed. Gregory Barz e Timothy Cooley. New York: Oxford University Press, 1997, p. 25-42.

TOMLINSON, Gary. Music in renaissance magic: Toward a historiography of others. Chicago: University of Chicago Press, 1994.

WEISS, Elisabeth. \& BELTON, John (eds.). Film Sound: Theory and Practice. New York: Columbia University Press, 1985. 